\title{
Influence of in vitro pigmenting of esthetic orthodontic ligatures on smile attractiveness
}

\author{
Camila Ferraz', Marcelo Castellucci², Márcio Sobral ${ }^{3}$
}

Objective: To evaluate the perception of dental students and orthodontists on the degree of influence that pigmented esthetic elastic ligatures have on smile attractiveness, by judging clinical photographs. Methods: Sixteen clinical facial photographs of the smile and 16 close up images of the smile of a single patient wearing monocrystalline porcelain orthodontic brackets, Teflon coated NiTi wire brackets and esthetic elastic ligatures of five different commercial brands were distributed into eight groups,

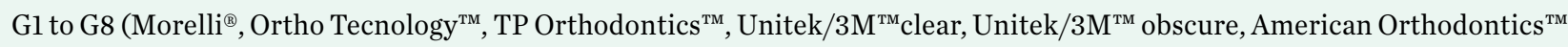
clear, American Orthodontics ${ }^{\mathrm{TM}}$ pearl and American Orthodontics ${ }^{\mathrm{TM}}$ metallic pearl). Twenty ligatures were used in each group, totaling 160 ligatures. Half of them were used in their natural state, and the other half after in vitro pigmentation. All the photographs were judged by 40 evaluators, 20 orthodontists and 20 dental students. Results: For orthodontists, American ${ }^{\mathrm{TM}}$ pearl

(G7) ligatures were those that least influenced the degree of attractiveness of the smile in the two types of photographs used. For the dental students, in the facial photographs of the smile, ligatures with the best performance were Morelli ${ }^{\circledR}(\mathrm{Gl})$, American ${ }^{\mathrm{TM}}$ clear (G6) and American ${ }^{\mathrm{TM}}$ pearl (G7) and in the close up photographs of the smile, American ${ }^{\mathrm{TM}}$ pearl, metallic pearl and clear (G7, G8 and G6). Conclusions: For both orthodontists and dental students, pigmentation of the elastic ligatures had a negative influence on the degree of attractiveness of smiles in the two types of clinical photographs evaluated.

Keywords: Elastomers. Esthetics. Pigmentation. Photograph. Smile.

Objetivo: avaliar, através de fotografias clínicas, entre estudantes de Odontologia e ortodontistas, o grau de influência que ligaduras elásticas estéticas pigmentadas exercem sobre a atratividade do sorriso. Métodos: foram utilizadas 16 fotografias clínicas faciais do sorriso e 16 de sorriso aproximado de um único paciente portando braquetes ortodônticos de porcelana monocristalina, fio de NiTi teflonado e ligaduras elásticas estéticas de cinco marcas comerciais diferentes, distribuídas em oito grupos, G1 a G8 (Morelli, Ortho Technology, TP Orthodontics, 3M/Unitek clear, 3M/Unitek obscure, American Orthodontics clear, American Orthodontics pearl e American Orthodontics metalic pearl). Foram utilizadas 20 ligaduras de cada grupo, totalizando 160 ligaduras. Metade delas foi utilizada em estado natural e a outra metade após pigmentação in vitro. Todas as fotografias foram julgadas por 40 avaliadores, sendo 20 ortodontistas e 20 estudantes de Odontologia. Resultados: para ortodontistas, as ligaduras American Orthodontics pearl (G7) foram as que menos influenciaram o grau de atratividade do sorriso nos dois tipos de fotografias utilizadas. Para os estudantes de Odontologia, nas fotografias faciais do sorriso, as que obtiveram o melhor desempenho foram Morelli (G1), American Orthodontics clear (G6) e American Orthodontics pearl (G7) e, nas fotografias de sorriso aproximado, American Orthodontics pearl, metalic pearl e clear (G7, G8 e G6, respectivamente). Conclusões: tanto para ortodontistas quanto para estudantes de Odontologia, a pigmentação das ligaduras elásticas influenciou de forma negativa o grau de atratividade dos sorrisos nos dois tipos de fotografias clínicas avaliadas.

Palavras-chave: Elastômeros. Estética. Pigmentação. Fotografia. Sorriso.

${ }^{1}$ Specialist in Orthodontics and Facial Orthopedics, Federal University of Bahia (UFBA). MSc Student in Dentistry, Federal University of Ceara (UFC).

${ }^{2} \mathrm{MSc}$ in Dentistry, UFBA; Specialist in Orthodontics and Facial Orthopedics, Catholic University of Minas Gerais (PUC-Minas). Professor of the Graduate Program in Orthodontics, UFBA.

${ }^{3}$ MSc in Orthodontics, Federal University of Rio de Janeiro (UFRJ). Professor of the Graduate Program in Orthodontics, UFBA. Diplomate by the Brazilian Board of Orthodontics.

How to cite this article: Ferraz C, Castellucci M, Sobral M. Influence of in vitro pigmenting of esthetic orthodontic ligatures on smile attractiveness. Dental Press J Orthod. 2012 Sept-Oct;17(5):123-30.
Submitted: September 31, 2011 - Revised and accepted: August 6, 2012.

» Patients displayed in this article previously approved the use of their facial and intraoral photographs.

» The authors report no commercial, proprietary, or financial interest in the products or companies described in this article.

Contact address: Camila Ferraz

Rua Dr. Gilberto Studart, 1369/702 - Cocó - Zip code: 60.192-095 - Fortaleza/CE - Brazil E-mail: dracamilaferraz@hotmail.com 


\section{INTRODUCTION}

Elastic ligatures are accessories commonly used in orthodontics and have wide application in holding the arch wires to the brackets.

Some laboratory studies have proved that these elastomeric materials are susceptible to pigmentation when in contact with some pigments, saliva and bacteria., ${ }^{1,23}$ This leads to a reduction in their useful life and compromises esthetics during the course of treatment. These alterations have a direct relationship with the composition, raw material quality and degree of technology used in their manufacture, which in turn, varies greatly according to each manufacturer., ${ }^{4,5,6}$

With the purpose of masking these pigments, many manufacturers add colors to ligatures, however, this procedure makes them unsuitable for use in esthetic appliances. Moreover, acceptance of the use of colored ligatures varies a great deal according to the patients' gender and age. ${ }^{7,8}$

Knowledge about the alterations in their physical and mechanical properties is of great interest for the clinical application of these materials, considering that they may remain in the oral cavity for an average of 30 days, and during this interval, it is very important for the properties with regard to elasticity and esthetics to remain stable., ${ }^{1,4,5,6,9,10,11}$

When evaluating the susceptibility to pigmentation of elastic orthodontic ligatures, some authors have used digital photographs and computerized analysis by means of the Adobe Photoshop program, and have concluded that these ligatures underwent change in color after an in vitro process of pigmentation. However, there are still no studies that prove the clinical relevance of these color alterations on the appearance of the orthodontic appliance set during the smile.

Evaluations made by means of photographs may be used to analyze color alterations of various types of dental materials, as well as in analyzing facial attractiveness and esthetics and of the smile, before, during and after orthodontic treatment by the most diverse

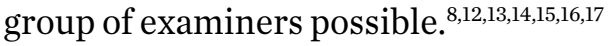

Knowing that the phenomenon of color is a psychophysical response to the light/object interaction, which depends on the individual subjective perception of the observer, and with the aim of obtaining greater knowledge about the esthetic influence of these pigmented elastomer materials on the appearance of the patient's smile during orthodontic treatment, makes it necessary to conduct clinical studies on the mentioned subject.

With this intention, the perception of the degree of influence esthetic elastic ligatures submitted to a process of pigmentation have on the attractiveness of the smile was evaluated between dental students and orthodontists by means of judging clinical photographs

\section{MATERIAL AND METHODS}

The present study is characterized by an experimental approach in which clinical facial photographs of the smile, and of the close up of a smile were used. The photographs had been taken of a single adult patient with a harmonious face and smile, ${ }^{14}$ who had adequate tooth alignment and leveling in the maxillary arch, required fixed orthodontic treatment, and wished to use an esthetic appliance.

The sample consisted of 16 clinical facial photographs of the smile $(12.8 \mathrm{~cm} \times 17.1 \mathrm{~cm})$ and 16 close up images of the smile $(19.2 \mathrm{~cm} \times 9.07 \mathrm{~cm})$ of a single patient.

The orthodontic appliance was composed of monocrystalline porcelain brackets (Ortho Technology ${ }^{\mathrm{TM}}$, Tampa, Florida, USA), NiTi wire 0.016-in Teflon coated (PTFE - polytetrafluorethylene), shade A2 (Beijing Smart Technology $\mathrm{CO}^{\mathrm{Tm}}$, Beijing, China) and esthetic elastic ligatures of five different commercial brands, distributed into eight groups, Gl to G8 (Morelli ${ }^{\circledR}$, Sorocaba, São Paulo, Brazil, Ortho Technology ${ }^{\mathrm{TM}}$, Tampa, Florida, USA, TP Orthodontics ${ }^{\mathrm{TM}}$, La Porte, Indiana, USA, Unitek $/ 3 \mathrm{M}^{\mathrm{TM}}$ clear, Unitek $/ 3 \mathrm{M}^{\mathrm{TM}}$ obscure, St. Paul, Minnesota, USA, American Orthodontics ${ }^{\mathrm{TM}}$ clear, American Orthodontics ${ }^{\mathrm{TM}}$ pearl and American Orthodontics $^{\mathrm{TM}}$ metallic pearl, Sheboygan, Wisconsin, USA).

Twenty ligatures were used in each group, totaling 160 ligatures. Half of them were used in their natural state, and the other half were submitted to an in vitro pigmentation process, as has previously been performed by other authors, ${ }^{2}$ by immersion in a solution composed of $250 \mathrm{ml}$ of each of the following solutions: coffee, black tea, red wine, Coca-Cola soft drink without gas, infusion made with a roll of tobacco and artificial saliva.

The ligatures were placed in disposable plastic cups, previously identified and separated into groups. The homogenized pigmentation solution was deposited into each of these cups covered with PVC film (polyvinyl chloride), and all the were stored in a plastic 
receptacle with a lid on, and placed in an oven (Biomatic - VOLT:220/110, AMP: $2 / 4$, WATTS: 400 ) at $37^{\circ} \mathrm{C}$ for five days. ${ }^{18}$ Five days of immersion was defined after conducting a pilot study in which the ligatures from all the groups went through a pigmentation process for ten days. Only on the fifth day was there evident visual differentiation between the degree of pigmentation and the ligatures in each of the evaluated groups.

After removing the cups from the oven, each of the ligatures was removed with Mathieu plier (Starlet ${ }^{\circledR}$, São Paulo, São Paulo, Brazil), rinsed in tap water for five seconds, dried with absorbent paper, stored in new, dry disposable plastic cups, also previously identified according to each group, and immediately used for taking the photographs.

The present study was approved by the Research Ethics Committee of the UFBASchool of Dentistry, Protocol Number 37/10 and registered with SISNEP FR 357694, CAAE 0023.0.368.000-10 on November 12, 2010.

After the patient had signed the Free and Informed Consent Term, the research began with placement of the maxillary fixed appliance from the central incisors to the second premolars. After the orthodontic brackets were bonded, the esthetic wire was introduced and fixed to the brackets by means of the elastic ligatures distended using the Mathieu pliers (Starlet ${ }^{\circledR}$, São Paulo, São Paulo, Brazil). Initially ligatures without pigmentation were used, and eight facial photographs were taken (F) and eight close up photographs of the smile (SA) (Fig 1). Afterwards, the same procedure was performed with pigmented ligatures, totaling 32 photographs. To distinguish the groups of photographs, those that were taken with pigmented ligatures had the letter "P" added (FP and SAP) (Fig 2).

To standardize the photographs, the patient's head was positioned with the aid of the head positioners of a cephalostat fixed to the clinic wall, in which the patient sat, with the Frankfort plane and bipupilar line parallel to the ground. In addition, the patient was instructed to keep a posed smile ${ }^{14,19}$ at the time the photographs were taken. In order to obtain a real front view contour of the patient's face, the two head positioners of the cephalostat were at the same distance from the camera, at $90^{\circ}$. This position was determined by the coincidence between the two points previously demarcated on the cephalostat with the
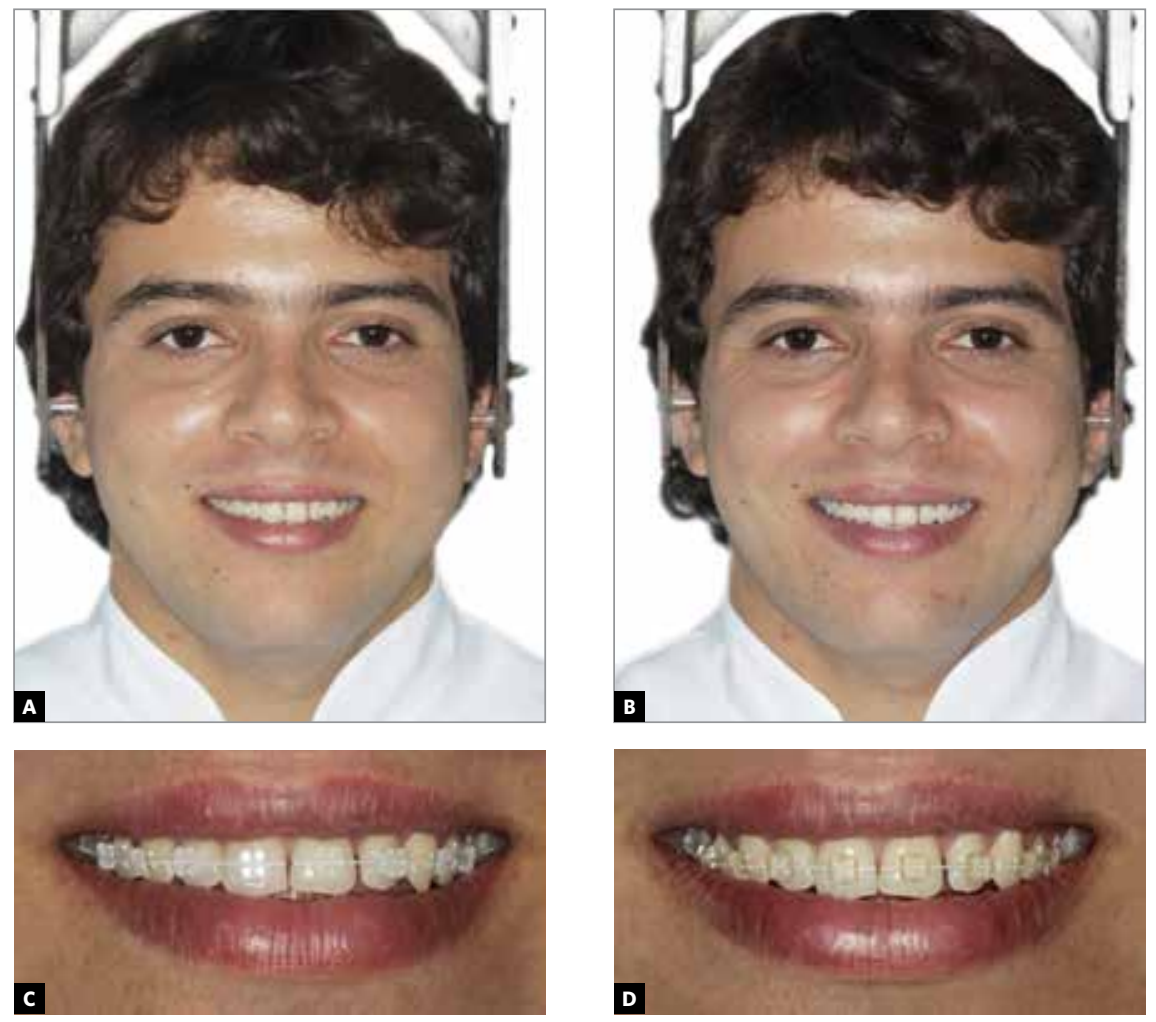

Figure 1 - Facial photographs of the smile: (A) without pigmentation and (B) with pigmentation. Close up photographs of the smile: (C) without pigmentation and (D) with pigmentation. 
Table 1 - Distribution of elastic ligatures in the sample of photographs. ${ }^{\star} \mathrm{G}$ - Group; F - Facial Photograph; FP - Pigmented Facial Photograph; SA - Close up Photograph of the Smile; SAP - Pigmented Close up Photograph of the Smile.

\begin{tabular}{|c|c|c|c|c|c|c|}
\hline \multirow{2}{*}{ Brand } & \multirow{2}{*}{ Shade } & \multirow{2}{*}{ Groups } & \multicolumn{2}{|c|}{ Facial photographs } & \multicolumn{2}{|c|}{ Close up photographs of the smile } \\
\hline & & & Without Pigmentation & With pigmentation & Without Pigmentation & With pigmentation \\
\hline Morelli & Cristal & G1 & G1F & G1FP & G1SA & G1SAP \\
\hline Ortho Technology & Pearl & G2 & $\mathrm{G} 2 \mathrm{~F}$ & G2FP & G2SA & G2SAP \\
\hline TP Orthodontics ${ }^{\mathrm{TM}}$ & Clear & G3 & G3F & G3FP & G3SA & G3SAP \\
\hline Unitek/3M & Clear & G4 & G4F & G4FP & G4SA & G4SAP \\
\hline Unitek/3M & Obscure & G5 & G5F & G5FP & G5SA & G5SAP \\
\hline American Orthodontics ${ }^{T M}$ & Clear & G6 & G6F & G6FP & G6SA & G6SAP \\
\hline American Orthodontics ${ }^{\top M}$ & Pearl & G7 & G7F & G7FP & G7SA & G7SAP \\
\hline American Orthodontics ${ }^{\mathrm{TM}}$ & $\begin{array}{c}\text { Metalic } \\
\text { Pearl }\end{array}$ & G8 & G8F & G8FP & G8SA & G8SAP \\
\hline TOTAL & & & 8 & 8 & 8 & 8 \\
\hline
\end{tabular}

aid of a protractor (Unitek/3M ${ }^{\mathrm{TM}}$, St. Paul, Minnesota, USA), one on the base and the other on the rotating support. ${ }^{20}$ This setting enabled one to record the patient's real facial image and her approximate smile.

Digital photographic equipment EOS Rebel-EOS Tl-i (Canon) was used, with a Macro EF 60 mm (Canon) lens and circular flash MR14EX (Canon), with exposure compensation of +1 . The distance between focus and object was $1.0 \mathrm{~m}$ for the facial photographs of the smile, and $44 \mathrm{~cm}$ for the smile close up. The speed used was $1 / 125 \mathrm{~s}$ with a diaphragm aperture of 8.0.

After having obtained the 32 photographs, an album was prepared, using eight pages of photographic paper Fujicolor Crystal Archive Paper $^{\circledR}$ (Fujifilm do Brasil Ltda., Manaus, Amazonas), size A3 (29.5 cm x $40.5 \mathrm{~cm})$ containing four photographs per page. All the images were named according to the group to which each commercial brand belonged, and whether or not they were pigmented. The order of disposition of each photograph in the album, facial (F) or close up smile (SA), was defined in increasing numerical order of the group of the commercial brand of ligatures. These numbers were randomly defined, and only the researcher responsible for the project had information about the commercial brand to which each group belonged. The first 16 photographs were facial, and the following were the close up smile, both non pigmented and pigmented in this sequence.

For esthetic evaluation of the smile, all the photographs were judged by 40 evaluators, of whom 20 were orthodontists, members of the Bahia Orthodontic Association - ABOR-BA - ("Associação de Ortodontia da Bahia"), aged between 28 and 58 years (mean of 37.8 years), with time since graduation ranging between one and 32 years (mean of 10.8 years) and 20 dental students, from the lst semester of the undergraduate course in dentistry at the Federal University of Bahia (UFBA, "Universidade Federal da Bahia"). Although these students already had a certain degree of instruction, at this academic stage, they did not yet have the technical-scientific knowledge of an orthodontist, and for the purpose of the present study, were considered lay persons. The number of evaluators was defined after sample calculation, in accordance with the mean obtained from the quantity of pigmentation, with a level of significance of $5 \%$ and power of $80 \%$.

Together with the photograph albums, each examiner received a form containing 32 rulers (visual analog scale), one for each photograph. Afterwards, they were asked to mark with a vertical line, the degree of satisfaction with the esthetics of the set formed by the brackets, wire and esthetic ligatures for each of the photographs. The evaluators were instructed that it would be possible to mark the line in any region of the ruler. The visual analog scale ${ }^{15,16,17,21,22}$ is $40 \mathrm{~mm}$ long, and on its extreme left, the words "VERY BAD" and on the extreme right "VERY GOOD" are written. The distance, in millimeters between the mark made by the evaluator of the photograph and the point at the extreme left served as measurement of the degree of attractiveness of each smile evaluated. ${ }^{21}$ The forms were applied to the examiners belonging to the group of dental students at the end of a regular undergraduate lesson. To the orthodontists, the forms were applied at the Orthodontic and Facial Orthopedic Center of Prof. José Édimo Soares 
Martins, or at his consulting rooms, so that the degree of lighting in these rooms was adequate and did not compromise evaluation of the photographs.

The data from each questionnaire were compiled in a spreadsheet, and after this, they underwent statistical treatment. Initially, the central trend and dispersion measurements were calculated, and after confirmation of normality of the data, the Student's $\mathrm{t}$-test and ANOVA were performed, with a level of significance of $5 \%$ to define the difference between them. The Kappa test was performed to evaluate agreement among the orthodontists themselves, among the dental students themselves, and between the dental students and orthodontists. For the orthodontists, Kappa 0.91 and among the dental students 0.87 was obtained, which means there was very good agreement among the evaluators of each group, but there was statistical difference between the two groups.

\section{RESULTS}

\section{Facial photographs of the smile}

The evaluation of the orthodontists and dental students varied with regard to the amount of loss of esthetics of the smile after pigmentation. According to the orthodontists, these alterations were very significant, as the smiles in which the patient was using the American $^{\mathrm{TM}}$ pearl (G7), American ${ }^{\mathrm{TM}}$ metallic pearl (G8) and Morelli ${ }^{\circledR}(\mathrm{Gl})$ were those that underwent the least alterations as regards degree of attractiveness. For the dental students these differences were smaller and the ligatures that least influenced the esthetics of the smile were Morelli ${ }^{\circledR}(\mathrm{Gl})$, American ${ }^{\mathrm{TM}}$ clear (G6) and American $^{\mathrm{TM}}$ pearl (G7) (Fig 2). Whereas those with the most unfavorable behavior, both from the point of view of orthodontists and dental students were ligatures of the Ortho Technology ${ }^{\mathrm{TM}}$ (G2) and Unitek/3M ${ }^{\mathrm{TM}}$ obscure (G5) commercial brands, respectively (Fig 2).

In the analysis of the absolute values with reference to the degree of attractiveness attributed to this type of photograph, it was verified that the orthodontists evaluated the smiles in which the ligatures were without pigmentation ( $\mathrm{F}$ ) as being more esthetic than the dental students did, whereas their scores for attractiveness of the smiles obtained higher means, and there were statistically significant differences in all the groups (Table 2). As regards the photographs with ligatures submitted to pigmentation (FP), the orthodontists were stricter and attributed lower scores to all groups, however, the majority without statistically significant difference, except for those in Group G8FP ( $\mathrm{p}=0.02$ ), in which the dental students did not identify the presence of important darkening in this group, and attributed much higher scores than the orthodontists did (Table 2). For the orthodontists, all the ligatures used were pigmented to a considerable extent.

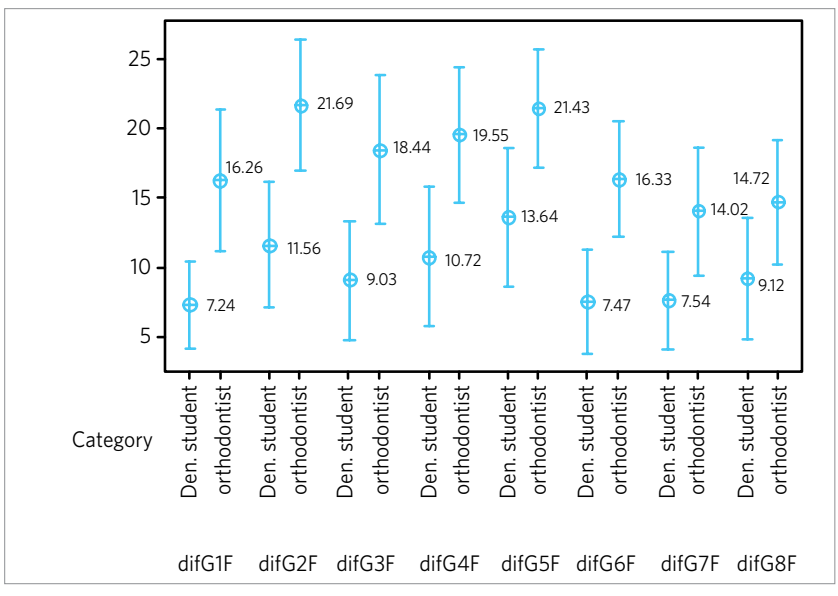

Figure 2 - Mean and standard deviation of the difference FP - F between the commercial brands and categories evaluated.

Table 2 - Mean, standard deviation F and FP and $p$ value of the difference between the professional categories in each group.

\begin{tabular}{cccc}
\hline Group & $\begin{array}{c}\text { Dentistry Students } \\
\text { mean (SD) }\end{array}$ & $\begin{array}{c}\text { Orthodontists } \\
\text { mean (SD) }\end{array}$ & p value \\
\hline G1F & $22.78(8.68)$ & $32.02(6.35)$ & $0.00^{\star}$ \\
G1FP & $16.99(9.42)$ & $15.85(10.04)$ & 0.70 \\
G2F & $27.17(7.41)$ & $34.61(5.35)$ & $0.00^{\star}$ \\
G2FP & $16.10(8.33)$ & $15.80(10.04)$ & 0.29 \\
G3F & $25.89(7.63)$ & $32.79(6.36)$ & $0.01^{\star}$ \\
G3FP & $17.13(9.16)$ & $14.35(11.11)$ & 0.39 \\
G4F & $27.59(7.58)$ & $33.90(6.09)$ & $0.01^{\star}$ \\
G4FP & $19.28(9.82)$ & $14.34(10.25)$ & 0.13 \\
G5F & $29.07(5.00)$ & $34.00(5.61)$ & $0.01^{\star}$ \\
G5FP & $15.52(10.11)$ & $12.57(9.38)$ & 0.35 \\
G6F & $28.73(6.53)$ & $33.68(6.17)$ & $0.02^{\star}$ \\
\hline G6FP & $22.32(8.90)$ & $17.35(9.39)$ & 0.09 \\
G7F & $26.03(8.65)$ & $33.18(6.09)$ & $0.01^{\star}$ \\
G7FP & $23.99(8.48)$ & $19.36(10.87)$ & 0.14 \\
G8F & $24.45(9.75)$ & $31.89(7.82)$ & $0.01^{\star}$ \\
G8FP & $24.28(7.85)$ & $17.17(9.72)$ & $0.02^{\star}$ \\
\hline
\end{tabular}

*Statistically significant difference. 


\section{Close up photographs of the smile}

In these photographs the orthodontists' and dental students' evaluation was very close as regards the amount of loss of esthetics after pigmentation. According to the orthodontists the smiles that showed smaller variations were those in which the patient was using American $^{\mathrm{TM}}$ pearl (G7) ligatures. Whereas for the dental students, they were American ${ }^{\mathrm{TM}}$ pearl (G7), metallic pearl (G8) and clear (G6) (Fig 3). Those with the most

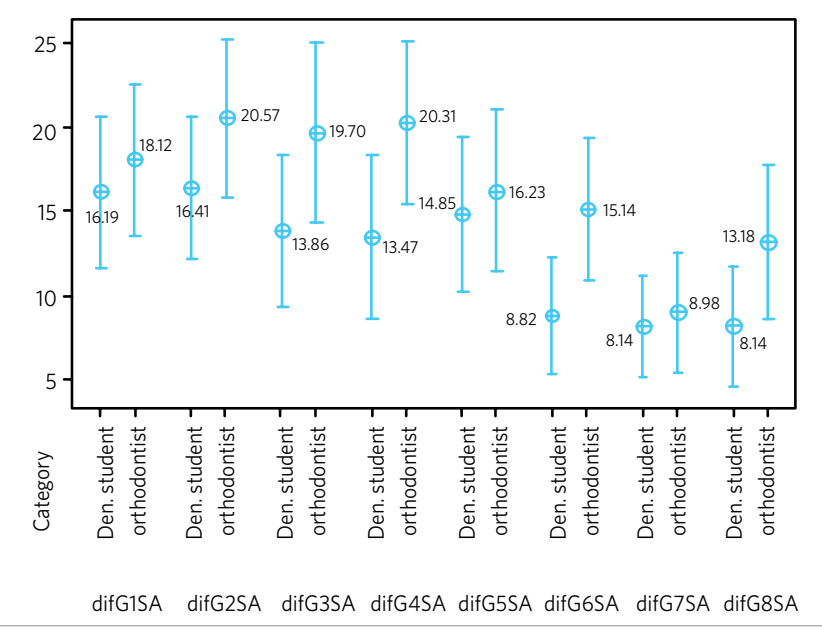

Figure 3 - Mean and standard deviation of the difference SAP - SA between the commercial brands and categories evaluated.

Table 3 - Mean, standard deviation SA and SAP and $p$ value of the difference between the professional categories in each group.

\begin{tabular}{|c|c|c|c|}
\hline Group & $\begin{array}{c}\text { Dentistry students } \\
\text { Mean (SD) }\end{array}$ & $\begin{array}{c}\text { Orthodontists } \\
\text { Mean (SD) }\end{array}$ & p value \\
\hline G1SA & $32.51(5.19)$ & $33.75(6.82)$ & 0.52 \\
\hline GISAP & $14.29(7.43)$ & 12.89 (8.59) & 0.59 \\
\hline G2SA & 31.79 (5.47) & $33.49(7.85)$ & 0.43 \\
\hline G2SAP & $11.84(7.34)$ & $10.46(7.72)$ & 0.57 \\
\hline G3SA & $30.95(5.23)$ & $34.05(6.38)$ & 0.10 \\
\hline G3SAP & $12.04(6.77)$ & 9.89 (7.93) & 0.36 \\
\hline G4SA & $30.85(7.86)$ & 34.65 (6.28) & 0.10 \\
\hline G4SAP & 11.77 (7.09) & $9.51(8.16)$ & 0.36 \\
\hline G5SA & $30.10(4.99)$ & $28.80(9.54)$ & 0.59 \\
\hline G5SAP & $13.39(8.11)$ & $8.56(6.25)$ & $0.04^{*}$ \\
\hline G6SA & $30.68(5.23)$ & $32.23(8.39)$ & 0.49 \\
\hline G6SAP & $15.44(7.04)$ & $12.12(8.05)$ & 0.17 \\
\hline G7SA & $29.26(5.32)$ & $25.40(10.70)$ & 0.16 \\
\hline G7SAP & $19.73(5.03)$ & $16.81(8.97)$ & 0.21 \\
\hline G8SA & $31.30(4.78)$ & $29.75(9.43)$ & 0.52 \\
\hline G8SAP & $19.12(9.68)$ & $12.23(7.67)$ & $0.02^{\star}$ \\
\hline
\end{tabular}

*Statistically significant difference. unfavorable behavior, according to the orthodontists, were Ortho Technology ${ }^{\mathrm{TM}}(\mathrm{G} 2)$, Unitek $/ 3 \mathrm{M}^{\mathrm{TM}}(\mathrm{G} 4)$ and TP Orthodontics ${ }^{\mathrm{TM}}$ (G3), respectively, and according to the dental students they were Ortho Technology ${ }^{\mathrm{TM}}(\mathrm{G} 2)$ and Morelli ${ }^{\circledR}$ (Gl) (Fig 3).

In the analysis of absolute values with reference to the degree of attractiveness attributed to this type of photograph, there was no clear difference between the evaluations made by dental students and orthodontists. Both groups attributed high scores to all the photos in which the ligatures were not pigmented (SA) and low scores to the majority of those with pigmented ligatures (SAP), except for those with Unitek $/ 3 \mathrm{M}^{\mathrm{TM}}$ obscure (G5SAP) $(\mathrm{p}=0.04)$ and American ${ }^{\mathrm{TM}}$ metallic pearl (G8SAP) ligatures $(p=0.02)$, in which the dental students did not observe important variations in the attractiveness of the smile (Table 3 ).

\section{DISCUSSION}

Some laboratory studies have proved that esthetic elastic ligatures are susceptible to pigmentation when in contact with some types of pigments ${ }^{1,2,3}$. Nevertheless, these color changes were observed only by means of a computer program, thus did not evaluate as from which point these alterations could be noted in daily life, and become disturbing to the patient.

In 2009, Cavalcante ${ }^{2}$ observed that the brand that showed the worst performance; that is to say, that became most pigmented was Unitek/ $3 \mathrm{M}^{\mathrm{TM}}$ obscure, which is confirmed by the present study, in which the commercial brands of ligatures that most compromised the degree of attractiveness of the smile clinically after pigmentation, in the evaluation by both orthodontists and dental students of the facial photographs of the smile were Unitek $/ 3 \mathrm{M}^{\mathrm{TM}}$ obscure (G5) and Ortho Technology $^{\mathrm{TM}}(\mathrm{G} 2)$. This could not be observed in the close up of the same, in which the data of these two studies differ, as the orthodontists indicated the brands Ortho Technology ${ }^{\mathrm{TM}}$ (G2), Unitek/3M ${ }^{\mathrm{TM}}$ clear (G4) and TP Orthodontics ${ }^{\mathrm{TM}}(\mathrm{G} 3)$ and the dental students the commercial brands Ortho Technology ${ }^{\mathrm{TM}}$ (G2) and Morelli ${ }^{\circledR}(\mathrm{Gl})$ as those that had the greatest degree of variation.

In the present study, according to the orthodontists, the degree of attractiveness of the smiles with the ligatures American ${ }^{\mathrm{TM}}$ pearl (G7) were those that underwent the smallest alterations in the two types of photographs used, which differs from the data 
previously found, ${ }^{2}$ in which the ligatures that became least pigmented were those of the TP Orthodontics ${ }^{\mathrm{TM}}$ and American ${ }^{\mathrm{TM}}$ Clear brands.

According to the dental students, the smiles that underwent the smallest variations were those in which the patient was using Morelli ${ }^{\circledR}(\mathrm{Gl})$, American $^{\mathrm{TM}}$ clear (G6) and American ${ }^{\mathrm{TM}}$ pearl (G7) ligatures in the facial photographs of the smile, and American ${ }^{\mathrm{TM}}$ pearl, metallic pearl and clear (G7, G8 and G6) in the close up photographs of the smile, obtaining a result close to those found by other authors, ${ }^{2,1}$ in which the American ${ }^{\mathrm{TM}}$ clear ligatures were also considered among the most stable.

Nevertheless, Cavalcante ${ }^{2}$ evaluated color changes by means of computerized comparison, using the Adobe Photoshop program RGB indices, color histogram observation at the level of red, green and blue of digital photographs of pigmented and unpigmented ligatures, instead of clinical evaluation of photographs, as was done in the present study. A similar evaluation was performed in another study ${ }^{1}$, in which the variation in ligature pigmentation was evaluated only by means of a color measuring device.

Thus, it could be concluded that the perception and interpretation of color are subjective, and can vary according to the type of evaluator. ${ }^{12,17}$ Moreover, an isolated numerical evaluation alone is not sufficient for an adequate observation of the color changes each elastic ligature undergoes, as the factors such as the oral environment itself and the set formed by the tooth, bracket and ligature may mask the results of color changes that have already been proved numerically.

Knowing that the degree of stability as well as the other physical and mechanical properties of each of these ligatures is directly related to its components and the particular manufacturing process of each of the commercial brands, it is important to understand that the variation between the natural, non pigmented state and pigmented state $(\Delta)$ is more important than the initial and final absolute color values of each of them, since we cannot ignore the initial characteristics inherent to the material ${ }^{1}$ which, undoubtedly, will have a repercussion on the final aspect of the ligature evaluated.

This fact associated with the interval between consultations during orthodontic treatment will have a direct influence on the indication and use of the esthetic elastic ligature, in the same way as it influenced the selection of the type of esthetic bracket. ${ }^{18}$ Therefore, before treatment begins, some aspects of esthetic accessories with respect to pigmentation must be explained to patients, so that unpleasant surprises concerning color alteration do not arise during the course of treatment.

In the present study, the pigmentation was performed in vitro, because of the difficulty of standardizing variables such as the patient's diet and oral habits during the entire period required for conducting the research. However, the number of days of immersion of the ligatures in the pigmentation solutions was defined so that it would very closely simulate the clinical pigmentation process so commonly observed in orthodontic practice. Thus, five days of immersion was defined after conducting a pilot study in which the ligatures from all the groups went through a pigmentation process for ten days. It may be observed that it was only on the fifth day that there was evident visual differentiation between the degree of pigmentation among the ligatures used in the study, and that as from this day, not only was there little difference among the groups, but the degree of pigmentation obtained was higher, with the ligatures being much darker than is routinely observed in clinical practice after an interval of 21 days between consultations.

The posed smile ${ }^{14,19}$ was used to enable visualization of the set formed by the tooth, bracket and ligatures. For this evaluation, the presence of subtle variables in the standardized photographs was not relevant to the investigation. Moreover, this research did not relate the color alterations with degradation of the effectiveness of elastic ligatures, and therefore, the brands with the best color stability may not necessarily correspond to the brands with the best clinical effectiveness. Thus, further studies must be conducted to elucidate this question.

It is therefore, of fundamental importance for the professional to know the behavior of esthetic ligatures before using them, because specific aspects of color, type of diet and time the ligature remains in the oral medium will influence the final esthetic appearance of the orthodontic appliance, and may frustrate the expectations of a patient who did not receive a previous explanation about the possibility of pigmentations. ${ }^{1,2}$ It is therefore the professional's responsibility to select the commercial brands for daily use, which provide the least loss in degree of attractiveness of the smile during the course of orthodontic treatments that require the use of esthetic devices. 


\section{CONCLUSIONS}

1) According to the orthodontists, there were alterations in the degree of attractiveness of the smile to a very significant extent when pigmented ligatures were used, with those of the American $^{\mathrm{TM}}$ pearl (G7) brand being the ones that underwent the smallest alterations in the two types of photographs used.

2) According to the dental students, these differences were smaller and the ligatures with the least influence on the attractiveness of the smile were Morelli ${ }^{\circledR}(\mathrm{Gl})$, American ${ }^{\mathrm{TM}}$ clear (G6) and American $^{\mathrm{TM}}$ pearl (G7) in the facial photographs of the smile, and American ${ }^{\mathrm{TM}}$ pearl, metallic pearl and clear (G7, G8 and G6) and in the close up photographs of the smile.

3) The ligatures that most compromised the degree of attractiveness of the smile, clinically, after pigmentation, both in the evaluation of orthodontists and dental students were Ortho Technology ${ }^{\mathrm{TM}}$ (G2) and Unitek/3M $\mathrm{M}^{\mathrm{TM}}$ obscure (G5) in the facial photographs of the smile. In the close up photographs of the smile, the orthodontists pointed out the brands Ortho Technology ${ }^{\mathrm{TM}}(\mathrm{G} 2)$, Unitek/3M ${ }^{\mathrm{TM}}$ clear (G4) and TP Orthodontics $^{\mathrm{TM}}$ (G3) and the dental students those of the brands Ortho Technology ${ }^{\mathrm{TM}}(\mathrm{G} 2)$ and Morelli ${ }^{\circledR}(\mathrm{Gl})$.
1. Ardeshna AP, Vaidyanathan TK. Colour changes of orthodontic elastomeric module materials exposed to in vitro dietary media. J Orthod. 2009 Sep;36:177-185.

2. Cavalcante J. Avaliação da suscetibilidade à pigmentação de ligaduras elásticas ortodônticas utilizando fotografia digital [Dissertação]. Salvador (BA): Universidade Federal da Bahia, Faculdade de Odontologia; 2009.

3. Kim S, Lee Y. Mensurement of discoloration of orthodontic elastomeric modules with a digital camera. Eur J Orthod. 2009 May;31:556-562.

4. Martins MM, Mendes AM, Almeida MAO, Goldner MTA, Ramos VF, Guimarães SS. Estudo comparativo entre as diferentes cores de ligaduras elásticas. Rev Dental Press Ortodon Ortop Facial. 2006 Jul-ago;11(4):81-90.

5. Taloumis LJ, Smith TM, Hondrum SO, Lorton L. Force decay deformation of orthodontic elastomeric ligatures. Am J Orthod Dentofac Orthop. 1997 Jan;111(1):1-11.

6. Wong AK. Orthodontic Elastic Materials. Angle Orthod. 1976 Apr;46(2):196-204

7. Elekdag-Turk S, Ozkalayci N, Isci D, Turk T. Color Preferences of Patients Receiving Elastic Ligatures. Eur J Dent. 2010 Apr;4:171-4.

8. Walton DK, Fields HW, Johnston WM, Rosenstiel SF, Firestone AR, Christensen JC. Orthodontic appliance preferences of children and adolescents. Am J Orthod Dentofac Orthop. 2010 Dec;138(6):698-9.

9. Loriato LB, Machado AW, Pacheco W. Considerações clínicas e biomecânicas de elásticos em ortodontia. Rev Clín Ortodon Dental Press. 2006 Fev-Mar;5(1):43-55.

10. Renick MR, Brantley WA, Beck FM, Vig KWL, Webb CS. Studies of orthodontic elastomeric modules. Part 1: Glass transition temperatures for representative pigmented products in the as-received condition and after orthodontic use. Am J Orthod Dentofac Orthop. 2004 Sep;126(3):337-43

11. Souza EV, Mendes AM, Almeida MAO, Quintão CCA. Percentual de degradação das forças liberadas por ligaduras elásticas. Rev Dental Press Ortodon Ortop Facial. 2008 Mar-Abr;13(2):138-45

12. Berto PM, Lima CS, Lenza MA, Faber J. Esthetic effect of orthodontic appliances on a smiling face with and without a missing maxillary first premolar. Am J Orthod Dentofac Orthop. 2009 Abr;135(4)supl.1:S55-S60
13. Delalíbera HVC, Silva MC, Pascotto RC, Terada HH, Terada RSS. Avaliação estética de pacientes submetidos a tratamento ortodôntico. Acta Sci Health Sci. 2010; 32(1):93-100.

14. Havens DC, McNamara Jr JA, Sigler LM, Baccetti $T$. The role of the posed smile in overall facial esthetics. Angle Orthod. 2010 Mar;80(2):322-328.

15. Maple JR, Vig KWL, Beck FM, Larsen PE, Shankere S. A comparison of providers' and consumers' perceptions of facial-profile attractiveness. Am J Orthod Dentofac Orthop. 2005 Dec;128(6):690-96.

16. Rosvall MD, Fields HW, Ziuchkovski J, Rosenstiel SF, Johnston WM. Attractiveness, acceptability, and value of orthodontic appliances. Am J Orthod Dentofac Orthop. 2009 Mar;135(3):276-7

17. Zange SE, Ramos AL, Cuoghi OA, Mendonça MR, Suguino R. Perceptions of laypersons and orthodontists regarding the buccal corridor in long- and short-face individuals. Angle Orthod. 2011 Jan;81(1):86-90.

18. Libório AO. Avaliação da suscetibilidade à pigmentação de brackets estéticos utilizando a fotografia digital [dissertação]. Salvador (BA): Universidade Federal da Bahia, Faculdade de Odontologia; 2006

19. Ackerman JL, Ackerman MB, Brensinger CM, Landis JR. A morphometric analysis of the posed smile. Clin Orthod Res. 1998 Aug;1(1):2-11.

20. Costa MCC, Barbosa MC, Bittencourt MAV. Avaliação da proporção facial vertical: relação das alturas tegumentar e esquelética. Rev Dental Press Ortodon Ortop Facial. 2011 Jan-Fev;16(1):99-106.

21. Scott SH, Johnston IE. The perceived impact of extraction and nonextraction treatments on matched samples of African American patients. Am J Orthod Dentofac Orthop. 1999 Sep;116(3):352-8.

22. Montini RW, McGorray SP, Wheeler TT, Dolce C. Perceptions of orthognathic surgery patient's change in profile. Angle Orthod. 2007 Jan;77(1);5-11. 